\title{
The plastic forming technology and die design of electric iron welding nozzle

\author{
Chen wei, Chen dan
}

Guangdong University of Science \& Technology, No.99 Xihu Road, Dongguan, Guangdong, 523083, China

278811242@qq.com

Keywords: Welding nozzle, plastic forming, cold extrusion, die design

\begin{abstract}
Welding technology is widely used in manufacturing, and welding nozzle directly affects the quality of its service life and the quality of weld. Welding mouth traditional forming process is machining, its material wastage rate is high, low production efficiency. This thesis makes a comparative study of the electric iron welding nozzle two different cold extrusion forming process. The results show that a backward extrusion forming than twice has more advantages on the forming load and the metal flow process. Finally this paper has carried on the design of the forming die.
\end{abstract}

\section{Introduction}

Welding is a common forming process, it is the principle of two or more than two kinds of welding parts into one of the process. Many manufacturing industry can not be separated from it, such as automobile manufacturing, all kinds of steel structure fabrication. And welding mouth is indispensable welding parts, the species abundance, but the manufacturing materials are all much of a muchness, good electrical and thermal conductivity. With the development of manufacture technology, manufacturing of welding mouth is also more and more efficient, and manufacturing mold and process of welding mouth are very important role to play. Forming processes is different because of different kinds of welding mouth. This research is with cold extruding forming technology to manufacture the electric iron welding nozzle.

\section{Technical requirements and features of parts}

The shape and size of the welding nozzle are as shown in Figure 1, for the thin-wall barrel shaped with sudden along parts. The selected material is CDA110 copper alloy, mechanical properties, tensile strength, $\sigma_{\mathrm{b}} \geqslant 275 \mathrm{MPa}, \delta_{10} \geqslant 5 \%, \delta_{5} \geqslant 10 \%$. Keep the excircle surface of the welding nozzle and is vertical to the bottom of it. Welding nozzle inner surface and outer surface accuracy requirement is not high, do not need to finish machining.

\section{Blank design and volume calculation}

Characteristics of extrusion: Extrusion parts of the size and stock volume in the before and after extrusion is constant. Thus, we can calculate the extrusion parts of the size, so as to determine the blank volume, will also be able to determine the blank size. Through 3D software Pro / e built model that volume model for $\mathrm{V}=5626.88 \mathrm{~mm}^{3}$. Here take blank diameter of $16 \mathrm{~mm}$, considered as the blank height $\mathrm{h}=28 \mathrm{~mm}$.CDA110 copper alloy density is $8.9 \mathrm{~g} / \mathrm{cm}^{3}$, calculate blank weight for $\mathrm{M}=50 \mathrm{~g}$. Then calculate the blank volume to determine the blank size (as shown in Figure 2) to carry out the material, can avoid in the material waste, saving material of the target can be reached. 


\section{Introduction of finite element model}

The paper uses the powerful DEFORM-3D bulk metal forming simulation software, using a 3D modeling software to set up geometric model and its assembly of the punch, die, blank, such as shown in Figure 3, and to *.STL format will import DEFROM-3D software, analog pre-processing settings.

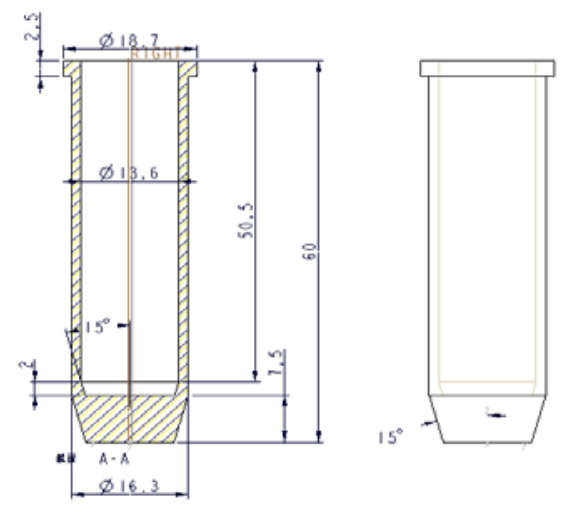

Fig.1 Part drawing

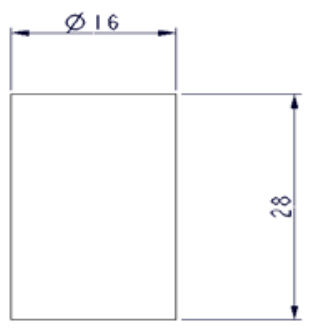

Fig.2 Blank size chart

\section{Design of cold extrusion process for welding nozzle}

Project one : A forming step by step, before heading back pre forming, extrusion forming. Project two: one step forming, direct back extrusion.

The forming process of the scheme and the scheme two are shown in Figure 3,4.
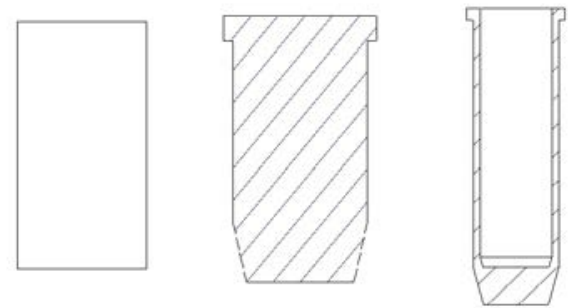

Fig.3 The step of project one
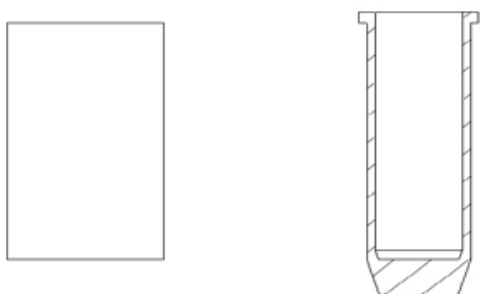

Fig.4The step of project two

\section{Analysis of numerical simulation results}

The paper uses powerful DEFORM-3D bulk metal forming simulation software, uses a 3D modeling software to build the geometric model of the punch, die, and blank.Then they will be assembled and to be *.STL format into the DEFROM-3D software, then simulation. Two schemes of die load analysis as shown in Figure 5 and Figure 6. 


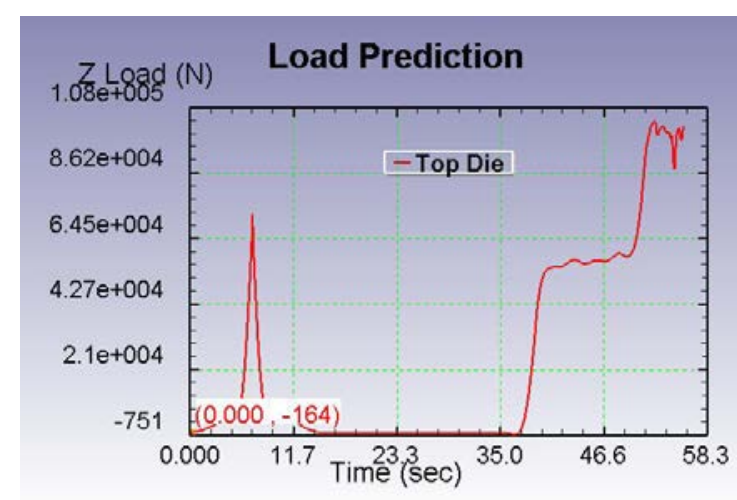

Fig.5 Load stroke of project one

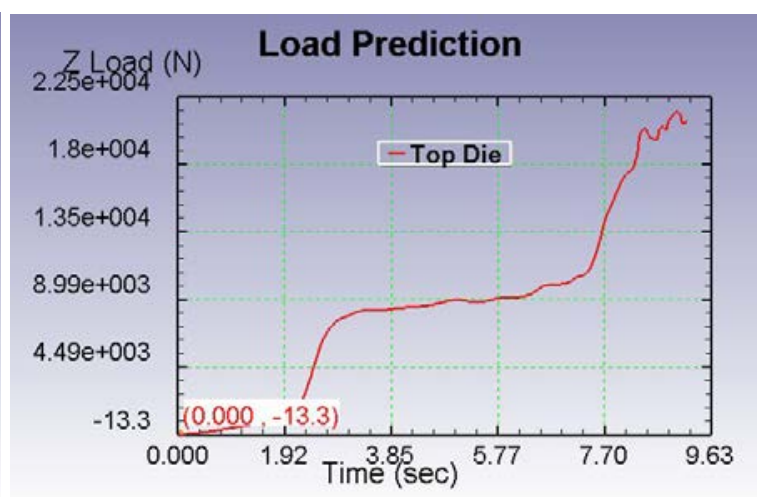

Fig.6Load stroke of project two

\section{Die load analysis:}

The load change of the scheme is not smooth, and the load average is greater than that of the scheme two. From the graph we can see that the load change is stable and the average load is less than the plan one.

\section{Comparative analysis of metal flow in the two scheme}

In the process of extrusion, the metal flow velocity and the direction of the metal in the billet are changed.

(1) The flow of metal is shown in Figure 7 whose has 3 different stages of metal flow during the extrusion process.

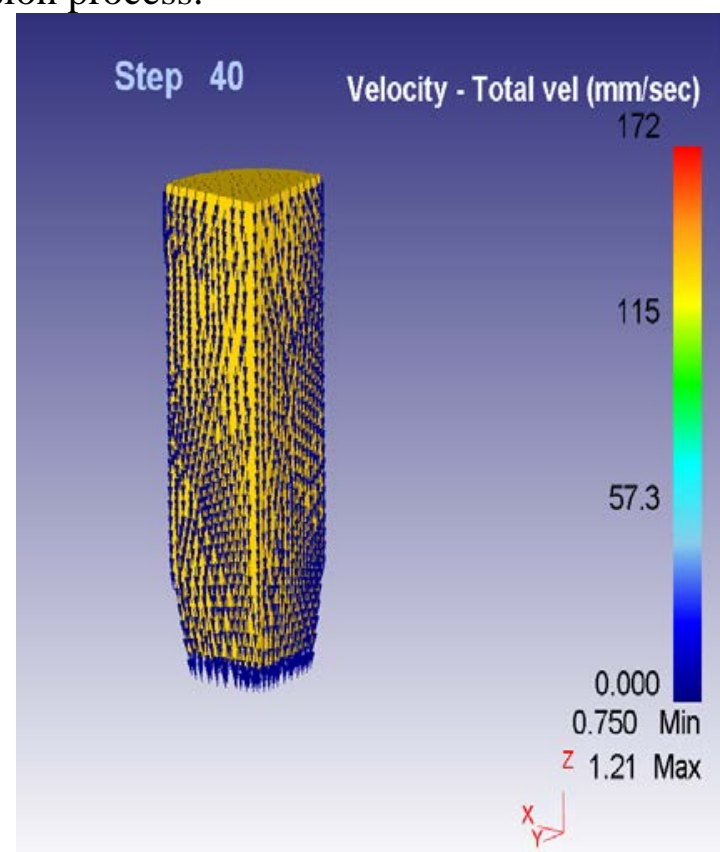

The first step

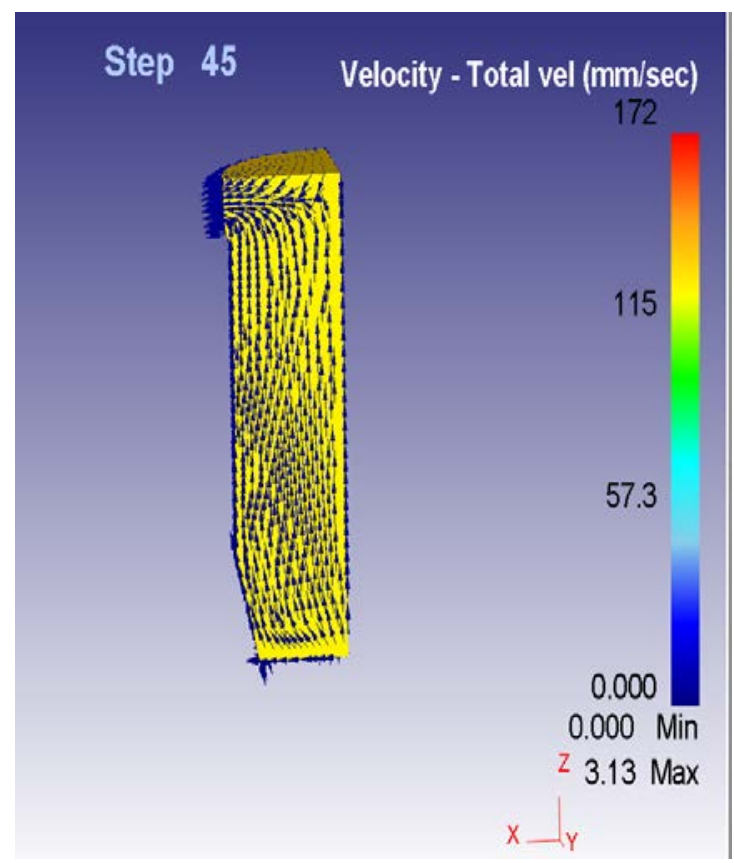

The second step 


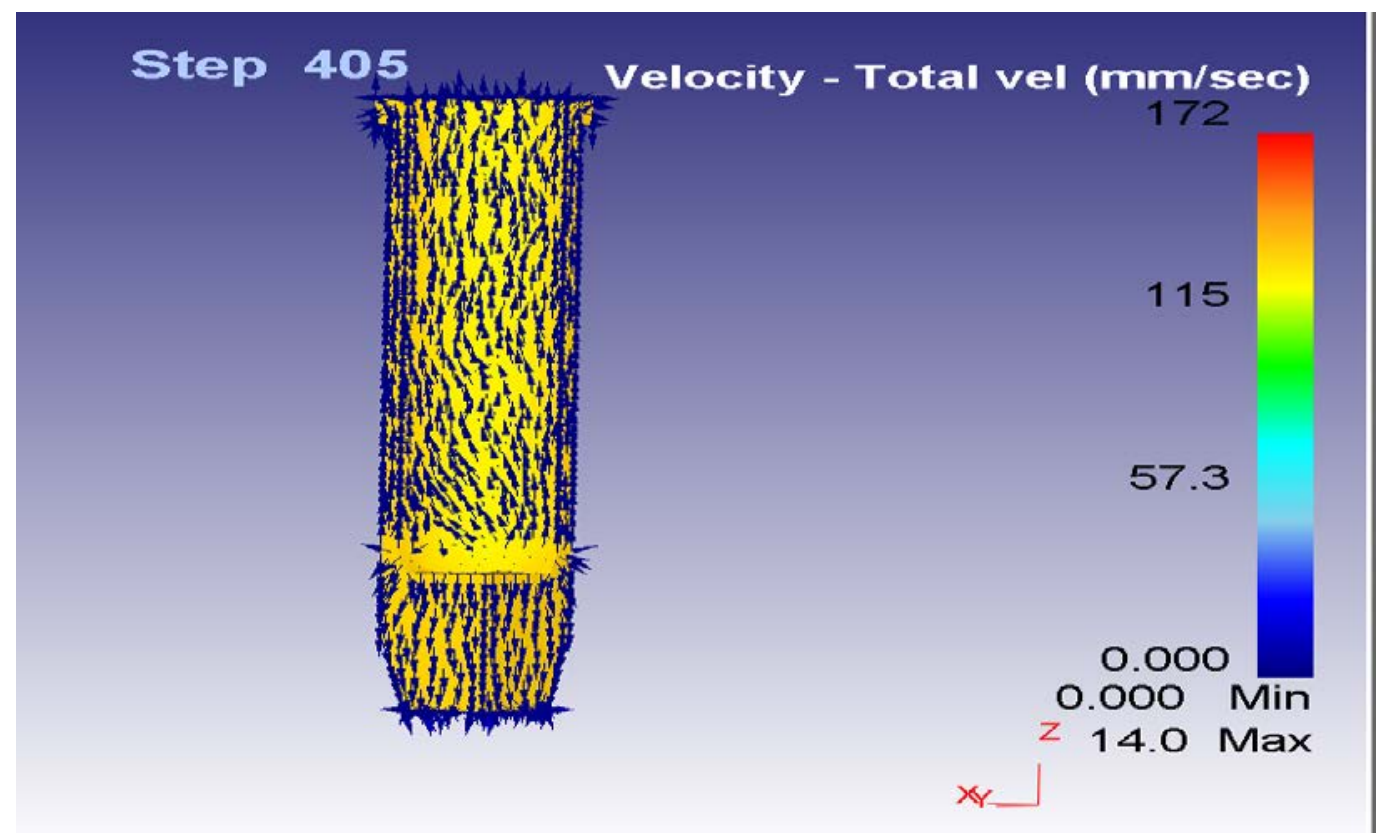

The third step

Fig.7 Metal flow at each stage of project 1

The first stage: blank upsetting, metal flow downward. Local deformation in the bottom of the blank, so the fastest velocity is in the bottom of the blank.

The second stage: upsetting, upsetting the metal to the lateral flow;

The third stage: forming stage, material flow is relatively stable. The metal flow velocity of upsetting part of billet is on the rise.

(2) The metal flow of the scheme two is shown in Figure 8, and the 3 time periods are taken as the same as the above.

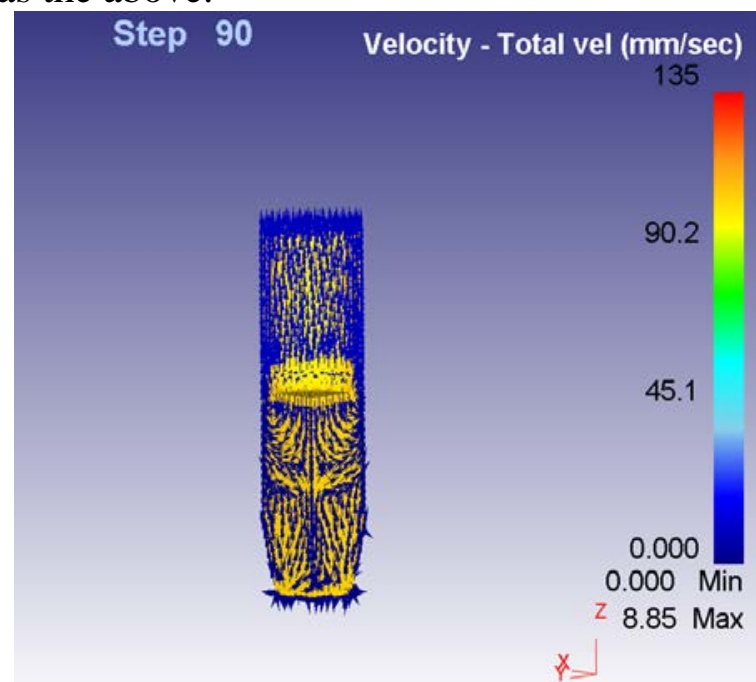

The first step

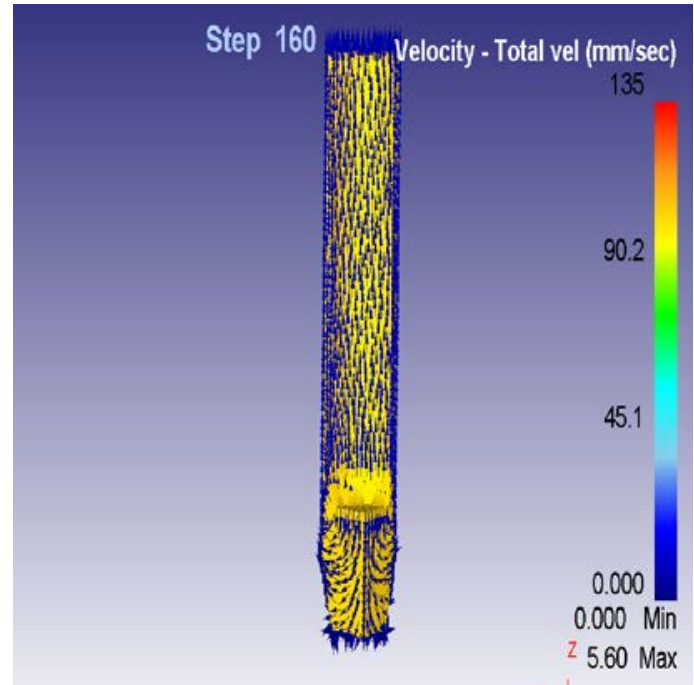

The second step 


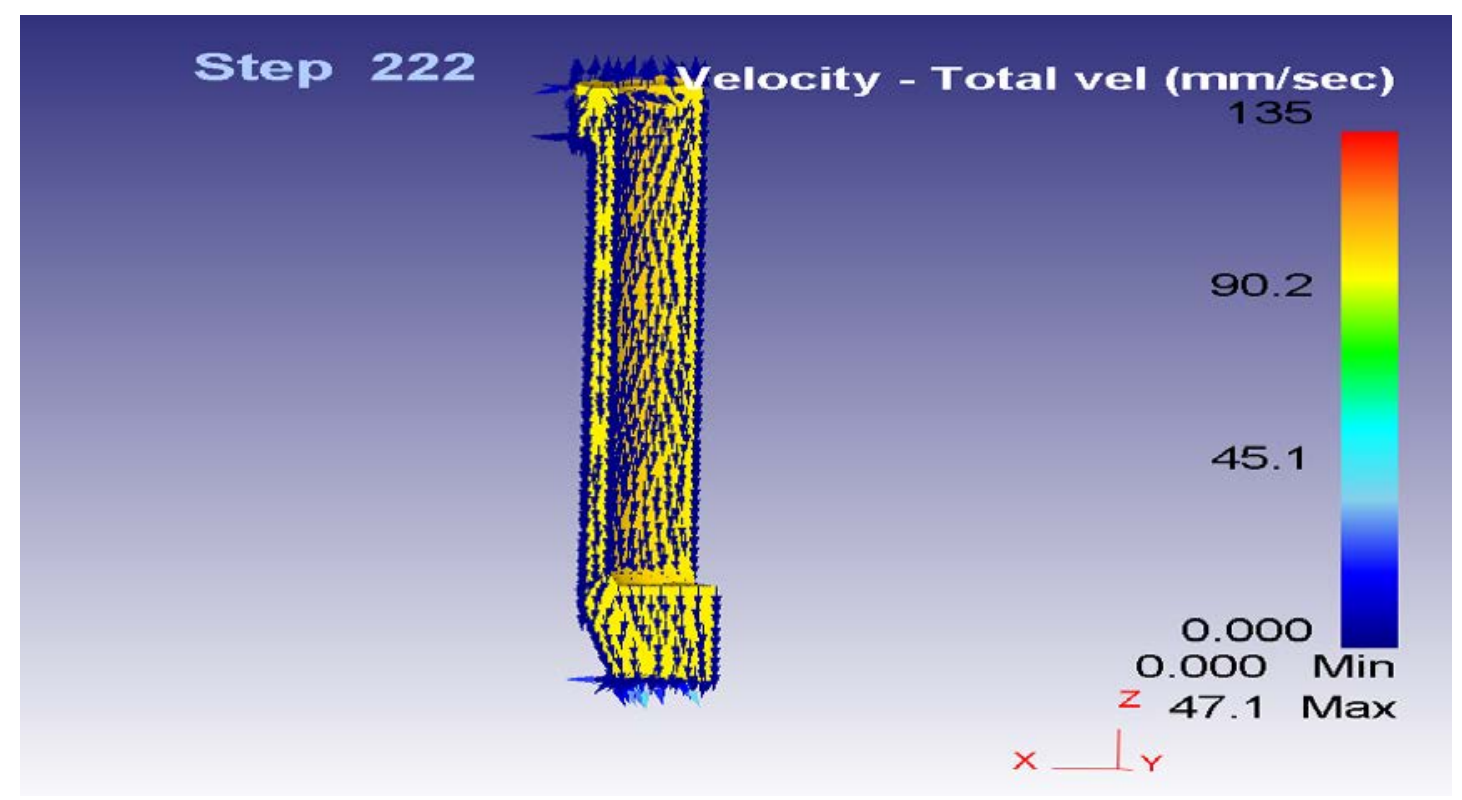

The third step

Fig. 8 Metal flow at each stage of project 2

From the figure can be seen in the first and second stage that metal flow velocity has little flow direction is upward. The metal flow velocity of the third stage is large and the flow direction downward. Metal mobility seems to be good .

(3) By the above can be compared with the solution of two of the metal mobility, second of the metal flow rate is relatively average, metal mobility is better than the program 1.

\section{Design of forging die}

The mold design structure of the anti extrusion process is shown in Figure 9. The mold is in the form of four guide columns, and the concave die is made of two layers of prestressed composite die.

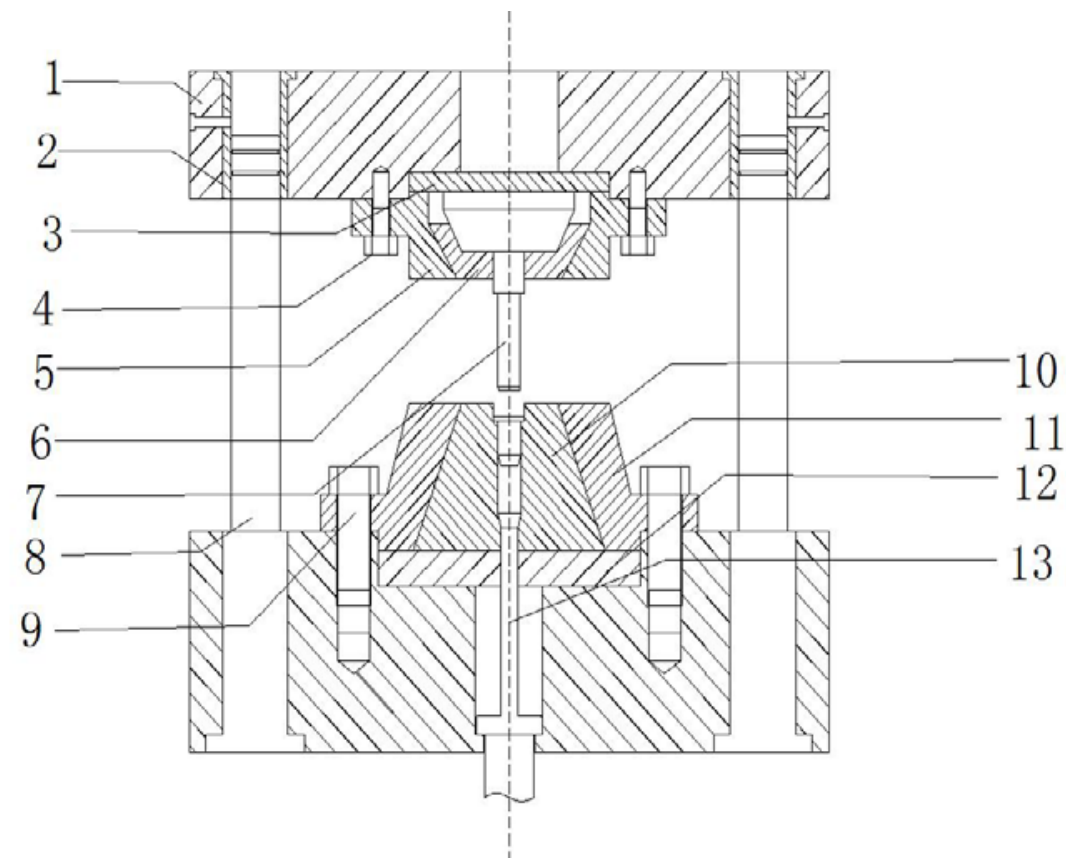

1 - template; 2 - guide sleeve; 3 - die base plate; 4 screws; 5 - the upper die seat; 6 - the heart die positioning block; 7- upper mould heart; 8 -pillar; 9 - screw; 10- die heart; 11- core positioning block; 12-die pads under; 13- push rod;

Fig.9 Anti extrusion die 


\section{Summary}

The more upsetting backward extrusion and a backward extrusion process of forming results, it is concluded that a backward extrusion has more advantages in the process, which is reflected in: save a procedure, improve the efficiency and reduce the cost; die load is smaller and more uniform, is conducive to improve the service life of the die; metal flow is more uniform, forming process is more stable.

\section{References}

[1] Xia, Guang. (2003). Thermal processing technology of straight spur gear cold forging process of the new value. Journal of thermal processing technology ,(2): 22-23.

[2] Chen ,Yan, Liu etc. (2016 ).Automobile heat radiating fins of the cold extrusion forming numerical simulation. Journal of thermal processing technology, (5) :160-162.

[3] Chen, Xu, Chen.( 2013).Influence of cold extrusion forming process on forming precision of cylindrical spur gear.Journal of casting technology, (1):115-117. 